\title{
Detection of Polymorphism on Voltage-gated Sodium Channel Gene of Indonesian Aedes aegypti Associated with Resistance to Pyrethroids
}

\author{
Budi Mulyaningsih ${ }^{1, *}$, Sitti Rahmah Umniyati ${ }^{1}$, Tri Baskoro Tunggul Satoto ${ }^{1}$, Ernaningsih ${ }^{1}$, \\ Dwi Aris Agung Nugrahaningsih ${ }^{2}$
${ }^{1}$ Department of Parasitology, Faculty of Medicine, Public Health and Nursing, Universitas Gadjah Mada, Jl. Farmako Sekip Utara, Yogyakarta 55281, Indonesia
${ }^{2}$ Department of Pharmacology, Faculty of Medicine, Public Health and Nursing, Universitas Gadjah Mada, Jl. Farmako Sekip Utara Yogyakarta 55281, Indonesia \\ *Corresponding author. E-mail: budi.mulyaningsih@ugm.ac.id
}

Received date: Jan 17, 2018; Revised date: Jul 11, 2018; Accepted date: Jul 25, 2018

\section{Abstract}

$\mathrm{B}$ ACKGROUND: Aedes aegypti is a vector of several pathogens including dengue virus. Vector control is an effective way to break the transmission but unfortunately constant use of insecticides ultimately causes vector resistance. Pyrethroids have been used for about 15 years to combat Ae. aegypti in Yogyakarta Province, Indonesia. Single amino acid substitutions in the voltagegated sodium channel associated with pyrethroid resistance constitute one of the main causative factors of knockdown resistance (kdr). The aim of this study is to detect resistant status to cypermetrine and polymorphism on the voltagegated sodium channel gene of Ae. aegypti from 2 dengue endemic areas in Yogyakarta Province (Yogyakarta city and Sleman district).

METHODS: Pyrethroid resistance in Ae. aegypti mosquitoes was detected by using CDC Bottle Bioassay. To detect the polymorphism on the voltage-gated sodium channel gene of Ae. aegypti analyses were conducted by using PCR and direct DNA squencing with primers AaSCF1 and AaSCR4 for S989P, I1011M (or V), L1014F sites, and AaSCF7 and AaSCR7 for the F1534C site.

RESULTS: According to bioassay, the results for Ae. aegypti from Yogyakarta city (93\% mortality) and Sleman district ( $88 \%$ mortality) suggest the possibility of resistance to cypermethrin. We observed polymorphism on voltagegated sodium channel gene on site F1534C (heterozygous).

CONCLUSION: The findings provide early evidence that the use of cypermethrin (pyrethroids) in Yogyakarta city and Sleman district, Yogyakarta Province, Indonesia is reducing its effectiveness to control Ae. aegypti. Recommendations include additional tests for confirmation.

KEYWORDS: Aedes aegypti, dengue virus, cypermethrin, Bioassay, Yogyakarta

Indones Biomed J. 2018; 10(3): 250-5

\section{Introduction}

Aedes aegypti (Linnaeus, Diptera: Culicidae) is the urban mosquito that transmits several pathogens including dengue virus in many tropical countries. The incidence of dengue and dengue haemorrhagic fever (DHF) is suspected to continue to increase in the near future.
This mosquito is highly anthropophilic, with markedly endophilic and endophagic behaviors; these characteristics are directly related to its high efficiency as a disease vector. $(1,2)$ In the absence of a vaccine or effective therapeutic medications, vector control remains the only available strategy to control and prevent dengue transmission.(1) Physiological resistance to insecticides often involves metabolic resistance either mutations in the insecticide 
target site (target-site resistance). Metabolic resistance to pyrethroid is usually associated with increased cytochrome P450 activity.(3)

Pyrethroids constitute a group of chemicals that are structurally modified by natural pyrethrum, and are composed of two main types. Most of the first generation pyrethroids are knockdown agents, which possess high knockdown activity but low killing activity; the second generation pyrethroids possess high killing activity. The use of knockdown agents such as d-allethrin and metofluthrin, which generally exhibit low stability in the environment as "spatial repellents" is biorational, because it causes low selection pressure on insect populations, thereby minimizing the development of physiological resistance. On the other hand, killing agents such as permethrin, deltamethrin, cypermethrin, and 1-cyhalothrin generally exhibit high photostability, and this enables their outdoor use in agriculture and their predominant application as vector control agents.(4) However, the high stability and killing efficacy of pyrethroids has accelerated the development of pyrethroid resistance in vector mosquitoes.(5)

Resistance to photostable pyrethroids is a major problem for the vector control program. Pyrethroid resistance involves two main mechanisms, namely, enhanced metabolic detoxification and insensitivity of target sites. Single amino acid substitutions in the voltage-gated sodium channel (VGSC), known as kdr mutations, constitute one of the main causative factors of pyrethroid resistance.(4) This kdr-type resistance has been observed in Ae. aegypti.(6)

Mutations in segment 6 of domain II of the VGSC (I1011M, I1011V, V1016G and V1016I) were reported to play important roles in pyrethroid resistance of Ae. aegypti. $(6,7,8,9)$ A F1534C mutation was detected in segment 6 of domain III in DDT/permethrin-resistant Ae. aegypti. $(10,11)$ The F1534C mutation was strongly correlated with resistance to DDT and pyrethroid.(12) The S989P mutation in domain II of the VGSC, which occurs in deltamethrinresistant $A e$. aegypti, is another principal kdr mutation that regulates pyrethroid resistance in mosquitoes.(13) Yanola, et al., reported the existence of the F1534C mutation in Ae. aegypti from Yangon City, Myanmar.(11) Kawada, et al., reported detailed genetic analyses of point mutations in the VGSC of Ae aegypti colonies in Myanmar.(4) However, no other genetic studies of point mutations in the VGSC of Ae. aegypti in Yogyakarta Province, Indonesia have been performed.

The objectives of the study were to detect pyrethroid resistance status in Ae. aegypti collected from Yogyakarta city and Sleman district, Indonesia, and look for any polymorphism in the VGSC gene. The targets were the four most frequent amino acid replacements in S989, I1011, L1014 and V1016, all of which are located in the area of segment 6 of domain II and also a recently identified amino acid replacement at F1534, located in the area of segment 6 of domain III.

\section{Methods}

Before starting this study, we have obtained ethical approval from the Medical and Health Research Ethics Committee, Faculty of Medicine, Public Health and Nursing, Universitas Gadjah Mada, Yogyakarta, Indonesia.

\section{Mosquito Collection}

Ae. aegypti mosquitoes of indigenous strain of Yogyakarta Province, Indonesia were subjected for the assays. They were collected from one site at two different dengue endemic areas, Yogyakarta city and Sleman district through indoor ovitraps surveys.

\section{Colonization}

The collected eggs were colonized in the laboratory to get adult stage. Morphology identification was done to adult mosquitoes to confirm the presence of Ae. aegypti species. Colonization of the mosquitoes were continued to obtain the F1 generation of adult stages. The same qualifications were also applied to mosquitoes from the Parasitology laboratory, Medical Faculty, Public Health and Nursing, Universitas Gadjah Mada Yogyakarta, Indonesia as negative control.

\section{Bioassay}

The bioassay followed the procedures for the Centers fo Disease Control and Prevention (CDC) Bottle Bioassay using adult female mosquitoes. According to this method, the diagnostic dose of cypermethrin was $10 \mu \mathrm{g} / \mathrm{bottle}$, whereas diagnostic time of cypermethrin was 30 minutes. Sample size was 100 mosquitoes for the initial test and 25 mosquitoes for the negative control.(14) The bioassay were replicated 3 times, total numbers of mosquitoes are 375 . The bioassays were conducted on the same day, in a room under optimum conditions $\left(\mathrm{t}=26^{\circ} \mathrm{C} \pm 2^{\circ} \mathrm{C} ; \mathrm{RH}=68 \pm 4 \%\right.$ ) for all experiments.

\section{Molecular Assay}

To identify the presence of polymorphism at S989, I1011, L1014, V1016 and F1534 in Ae. aegypti, we used polymerase chain reaction (PCR) and direct DNA 
sequencing.(4) The mosquito samples were lightly dried on a paper towel and placed in a $1.5 \mathrm{~mL}$ PCR reaction tube. The DNA was extracted from mosquito pools using DNA Mini Kit GeneaidTM Cat No. \#GB100. Lot No. JM02202 following the manufacture's instructions. Amplification was accomplished in $25 \mu \mathrm{L}$ volumes, using the protocols supplied by Go Taq Green Master Mix (Promega, Wisconsin, USA). The solution was heated at $95^{\circ} \mathrm{C}$ for 3 minutes and neutralized. Initial amplification was carried out using the primers AaSCF1 (AGACAATGTGGATCGCTTCC) and AaSCR4 (GGACGCAATCTGGCTTGTTA) for S989P, I1011M (or V), L1014F and V1016G (or I); or AaSCF7 (GAGAACTCGCCGATGAACTT) and AaSCR7 (GACGACGAAATCGAACAGGT) for F1534C. The PCR mixture contained $4 \mathrm{~mL}$ of REDExtract-N-Amp ReadyMix (Sigma), $0.5 \mathrm{~m} \mathrm{M}$ of each primer, and $1 \mathrm{~mL}$ of the DNA template in a total volume of $10 \mathrm{~mL}$. The PCR was performed under the following conditions: initial denaturation at $94^{\circ} \mathrm{C}$ for 3 minutes; 35 cycles each of $94^{\circ} \mathrm{C}$ for 15 seconds, $55^{\circ} \mathrm{C}$ for 30 seconds and $72^{\circ} \mathrm{C}$ for 30 seconds and a final elongation step at $72^{\circ} \mathrm{C}$ for 10 minutes. The amplified fragments of the expected size were purified with ExoSAPIT (USB Corporation, Cleveland, OH, USA) at $37^{\circ} \mathrm{C}$ for 30 minutes, and then $800 \mathrm{C}$ for 15 minutes. The DNA sequencing was carried out by First Base Laboratories. The chromatogram analysis were performed using free software Chromaslite ${ }^{\circledR}$ version 2.6.4 (Technelysium Pty Ltd, South Brisbane, Australia). Sequences were aligned using BLAST nucleotide at http://www.ncbi.nlm.nih.gov/blast/.

\section{Results}

The results of bioassay with cypermethrin (pyrethroids) at the CDC diagnostic dose and its diagnostic time for $A e$. aegypti adult mosquitoes from Yogyakarta city and Sleman district are given below in Table 1.

Table 1. The mean of percentage mortalities in the CDC bottle bioassay of adult female of Ae. aegypti from Yogyakarta city and Sleman district for evaluating insecticide resistance to diagnostic dose and diagnostic time of cypermethrin.

\begin{tabular}{ccc}
\hline \multirow{2}{*}{$\begin{array}{c}\text { CDC Bottle } \\
\text { Bioassay }\end{array}$} & \multicolumn{2}{c}{ Mosquitoes Mortality Percentage (\%) } \\
\cline { 2 - 3 } & Yogyakarta City & Sleman District \\
\hline I & 93 & 92 \\
II & 90 & 90 \\
III & 96 & 82 \\
\hline Mean & $93 \pm 2.45 \%$ & $88 \pm 4.32 \%$ \\
\hline
\end{tabular}

*diagnostic dose: $10 \mathrm{ug} / \mathrm{bottle}$ **diagnostic time: 30 minutes.
At diagnostic dose of $10 \mu \mathrm{g} /$ bottle an diagnostic time 30 minutes, mosquitoes mortality percentage were $93 \pm 2.45 \%$ and $88 \pm 4.32 \%$ for the mosquitoes from Yogyakarta city and Sleman district respectively. Futher study was done as an effort to know the mechanism of the decrease sensitivity of the mosquitoes in Yogyakarta city and Sleman district towards cypermethrin (pyrethroids) using PCR technique followed by sequencing of VGSC gene.

The PCR assay with the primers AaSCF1 (AGACAATGTGGATCGCTTCC) AaSCR4 (GGACGCAATCTGGCTTGTTA) showed specific DNA bands with the size of 619bp (Figure 1 A) and with primers AaSCF7 (GAG AAC AAC ATG CCG TCG TT) and AaSCR7 (GAC GAC GAA GAA CAG ATC GT) showed specific DNA bands with the size of 748bp (Figure $1 \mathrm{~B}$ ). The specific DNA band indicates the development of resistance in Ae. aegypti mosquitoes to pyrethroid insecticide.

The results of sequencing analysis VGSC gene of Ae. aegypti from Yogyakarta city and Sleman district with primers AaSCF1 and AaSCR4 (accession No. AB914689 and AB914690) no polymorphism on sites S989, I1011, L1014 and V1016. Sequencing analysis VGSC gene of Ae. aegypti from Yogyakarta city with primers AaSCF7

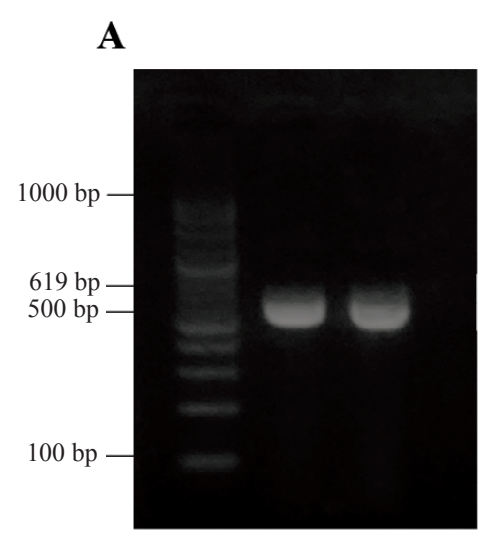

B

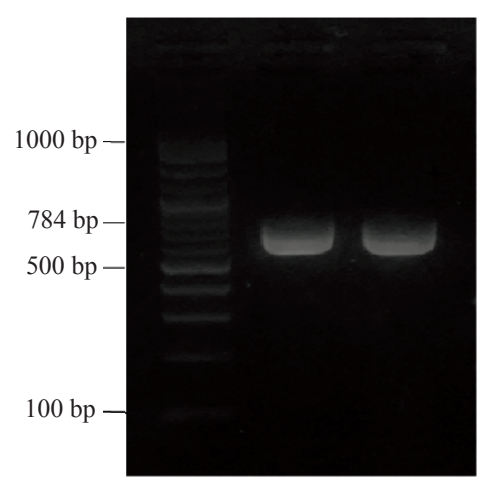

Figure 1. Amplification DNA genom of Ae. aegypti from Yogyakarta city and Sleman district, Indonesia. 
and AaSCR7 (Accession No. AB914687 and AB914688), showed no polymorphism on site F1534, whereas Ae. aegypti from Sleman district showed polymorphism on site F1534 (heterozygous). The data are given below in Table 2 .

\section{Discussion}

Pyrethroid insecticides were used for dengue control in Yogyakarta Province since about 15 years ago and have been constantly used till now. This intensive use may explain the strong selection pressure toward Ae. aegypti, because this mosquito is generally a domestic and endophagic species with a preference for indoor breeding. The widespread use of chemical insecticides has led to the development of insecticide resistance in several insects including mosquitoes.(15)

Insecticide resistance is often a complex dynamic interplay of several mechanisms. The most resistance mechanisms can be divided into two groups, metabolic (alterations in the levels or activities of detoxification proteins), and target site (mutations in the sodium channel, acetylcholinesterase and gamma-aminobutyric acid (GABA) receptor genes). Alone or in combination these mechanisms confer resistance, sometimes at an extremely high level, to all of the available classes of insecticides. (16) Resistance mechanism in Ae. aegypti from Yogyakarta city maybe due to metabolic resistance (alterations in the levels or activities of detoxification proteins). Metabolic resistance to pyrethroid is usually associated with increased cytochrome $\mathrm{P} 450$ activity. 3

The World Health Organization (WHO) recommendations for assessing the significant chance of detected resistance is $98 \%-100 \%$ mortality at the recommended diagnostic time indicating susceptibility, $80 \%-97 \%$ mortality at the recommended diagnostic time suggesting the possibility of resistance, which needs to be confirmed, and less than $80 \%$ mortality at the recommended diagnostic time suggesting some resistance.(14) According to WHO's recommendation, Ae. aegypti from Yogyakarta city and Sleman district, Indonesia suggest the possibility of resistance to cypermethrin, wich needs to be confirmed. Where $<95 \%$ mortality occurs at the diagnostic time in bioassays that have been conducted under optimum conditions and with a sample size of $>100$ mosquitoes, then resistance can be strongly suspected.(14) This study conducted under optimum condition $\left(\mathrm{t}=26^{\circ} \mathrm{C} \pm 2^{\circ} \mathrm{C}\right.$; $\mathrm{RH}=68 \pm 4 \%$ ), and the sample size were 300 mosquitoes. These data may provide early evidence that cypermehtrin (Pyrethroids) is losing its effectiveness.

Yogyakarta city and Sleman district are neighboring districts, and therefore the two areas share environmental, sociological, and biological similarities. As a result, study to clarify polymorphism on VGSC gene between the two Ae. aegypti population in Yogyakarta city and Sleman district, which may have exchanged or developed introgression of genes, is required.

The amino acid changes in Ae. aegypti mosquitoes were most frequently observed at the points S989, I1011, L1014 and V1016, which are located in segment 6 of domain II. Current identification indicates that the amino acid replacement in F1534 is located in the segment 6 of domain III.4 The existence of the VGSC gene mutation plays a role in the development of resistance.

In this study the VGSC gene polymorphism occur on site F1534 (heterozygous), whereas no polymorphism was seen on sites S989P and V1016G in Ae. aegypti from Sleman district. After the first description of the newly identified F1534C point mutation in Ae. aegypti collected in Thailand, the same mutation was reported in Vietnam, Brazil, Venezuela, Madeira Island, Portugal and Grand Cayman Island in UK.(4) In that study, findings determined

Table 2. Sequence analysis of segments 6 domain II and III of the voltage-gated sodium channel gene of Ae. aegypti from Yogyakarta city and Sleman district, Indonesia.

\begin{tabular}{|c|c|c|c|c|}
\hline $\begin{array}{l}\text { Polymorphism } \\
\text { of the gene }\end{array}$ & $\begin{array}{c}\text { Segments } 6 \text { domain II } \\
\text { of Ae. aegypti from } \\
\text { Yogyakarta city }\end{array}$ & $\begin{array}{c}\text { Segments } 6 \text { domain II } \\
\text { of } A e . \text { aegypti from } \\
\text { Sleman district }\end{array}$ & $\begin{array}{c}\text { Segments } 6 \text { domain III } \\
\text { of } A e \text { aegypti from } \\
\text { Yogyakarta city }\end{array}$ & $\begin{array}{l}\text { Segments } 6 \text { domain III } \\
\text { of Ae. aegypti from } \\
\text { Sleman district }\end{array}$ \\
\hline S989P & S989 / S989 & S989 / S989 & - & - \\
\hline $\mathrm{I} 1011 \mathrm{M} / \mathrm{V}$ & I1011 / I1011 & I1011 / I1011 & - & - \\
\hline V1016G/I & V1016 / V1016 & V1016 / V1016 & - & - \\
\hline F1534C & - & - & F1534 / F1534 & F1534 / F1534C* \\
\hline
\end{tabular}

*Polymorphism of the gene F1534 / F1534C (heterozygous). 
a moderate frequency of this point mutation in Yangon City $(21.2 \%)$, this frequency was of a comparable level to that recorded in Vietnam (average, 21.6\%) but lower than the frequencies recorded in Thailand (59-79\%), Grand Cayman Island (68\%) and Venezuela (100\%).(4) Elucidation of the worldwide distribution of the F1534C mutation in Ae. aegypti and Aedes albopictus will provide a valuable insight into DHF epidemiology, and yield useful information for vector control programs. In the present study, were detected three patterns of cooccurrence of point mutations, namely, V1016G/S989P, V1016G/F1534C, and V1016G/F1534C/ S989P. The S989P mutation has always been linked to the V1016G mutation, however, V1016G has sometimes been found in the absence of S989P.(15) The cooccurrence of V1016G and S989P enhanced the resistance of Ae. aegypti to deltamethrin.(17)

The Aedes mosquito control unit was established in 1968, and several feasibility studies aimed at the development of Ae. aegypti control methodology, including insecticide treatment, biological control by using larvivorous fish, environmental improvement, and health education, were undertaken.(18) However, current information regarding insecticide use for DHF vector control in Indonesia is lacking, and few studies concerning the insecticide resistance of DHF vectors have been published.

Pyrethroids represent one of the most promising countermeasures for controlling malaria, DHF and other arthropod-borne diseases. Currently, there are no suitable chemical substitutes for pyrethroids, and therefore pyrethroid resistance will continue to be a major problem for vector control programs.(19) The development of new chemicals with novel modes of action, which can be substituted for conventional insecticides, is essential. Transitional life-prolonging measures for conventional $1^{\text {st }}$ generation pyrethroids that belong to the photo-unstable knockdown agent groups and are used as "spatial repellents", rotational use of plural insecticides with different mode of actions, and basic biochemical and genetic research to support the above strategies, are crucial to the effective management of insecticide resistance. $(20,4)$

\section{Conclusion}

Ae. aegypti from Yogyakarta city and Sleman district, Yogyakarta Province, Indonesia are suggests the possibility of resistance to cypermethrin, which needs to be confirmed. The VGSC gene was observed on site F1534 showed polymorphism (heterozygous) in Ae. aegypti from Sleman district. The findings provide early evidence that the use of cypermethrin (pyrethroids) in Yogyakarta city and Sleman district, Yogyakarta Province, Indonesia is losing its effectiveness to control Ae. aegypti. Recommendations include additional tests to observe cytochrome $\mathrm{P} 450$ activity.

\section{Acknowledgment}

We give thanks to Mr. Purwono, Mrs. Rumbiwati and Mrs. Kuswati, technicians of the Parasitology Department, Faculty of Medicine, Public Health and Nursing, Universitas Gadjah Mada, Yogyakarta, Indonesia, for mosquitoes collection and providing technical support, for colonization and providing the experimental insects, and for assisting with this study. We are grateful to the Faculty of Medicine, Public Health and Nursing, Universitas Gadjah Mada Yogyakarta, Indonesia for giving us funding through the Community Funding 2016 and providing facilities for the study.

\section{References}

1. World Health Organization. Dengue Guidelines for Diagnosis, Treatment, Prevention and Control: New Edition. Geneva: World Health Organization; 2009

2. Scott TW, Morrison AC. Vector dynamics and transmission of dengue virus: implications for dengue surveillance and prevention strategies: vector dynamics and dengue preventn. Curr Top Microbiol Immunol. 2010; 338: 115-28

3. Berge JB, Feyereisen R. Amichot M. Cytochrome P450 monooxygenases and insecticide resistance in insects. Philos Trans R Soc Lond Biol. 1998; 353: 1701-5.

4. Kawada H, Sai ZMO, Sein T, Emiko K, Yan NMM, Hlaing MT, et al. Co-occurrence of point mutations in the voltage-gated sodium channel of pyrethroid-resistant Aedes aegypti populations in Myanmar. PLoS Negl Trop Dis. 2014; 8: e3032. doi: 10.1371/ journal.pntd.0003032.

5. Kawada H. An inconvenient truth of pyrethroid - does it have a promising future? In: Clark J, Bloomquist JR, Kawada H, editors. Advances in Human Vector Control (ACS Symposium Book 1014). New York: American Chemical Society; 2009.

6. Brengues C, Hawkes NJ, Chandre F, McCaroll L, Duchon S, et al. Pyrethroid and DDT cross-resistance in Aedes aegypti is correlated with novel mutations in the voltage-gated sodium channel gene. Med Vet Entomol, 2003; 17: 87-94.

7. Saavedra-Rodriguez K, Urdaneta-Marquez L, Rajatileka S, Moulton $\mathrm{M}$, Flores $\mathrm{AE}$, et al. A mutation in the voltage-gated sodium channel gene associated with pyrethroid resistance in Latin American Aedes aegypti. Insect Mol Biol, 2007; 16: 785-98.

8. Chang C, Shen WK, Wang TT, Lin YH, Hsu EL, et al. A novel amino acid substitution in a voltage-gated sodium channel is associated with knockdown resistance to permethrin in Aedes aegypti. Insect Biochem Mol Biol. 2009; 39: 272-8. 
9. Ghiffari A, Fatimi H, Anwar C. Detection of insecticide synthetic pyrethroid resistance on dengue vector Aedes aegypti (L.) in Palembang using Polymerase Chain Reaction. Aspirator. 2013; 5: 37-44.

10. Yanola J, Somboon P, Prapanthadara L. A novel point mutation in the Aedes aegypti voltage-gated sodium channel gene associated with permethrin resistance. In: The 2nd International Conference on Dengue and Dengue Haemorhagic Fever, Oct. 15-17, 2008. Phuket, Thailand.

11. Yanola J, Somboon P, Walton C, Nachaiwieng W, Somwang P, et al. High-throughput assays for detection of the F1534C mutation in the voltagegated sodium channel gene in permethrin-resistant Aedes aegypti and the distribution of this mutation throughout Thailand. Trop Med Int Health, 2011; 16: 501-9.

12. Harris AF, Rajatileka S, Ranson H. Pyrethroid resistance in Aedes aegypti from Grand Cayman. Am J Trop Med Hyg 2010; 83: 277 84.

13. Srisawat R, Komalamisra N, Eshita Y, Zheng M, Ono K, et al. Point mutations in domain II of the voltage-gated sodium channel gene in deltamethrin-resistant Aedes aegypti (Diptera: Culicidae). Appl Entomol Zool, 2010; 45: 275-282.
14. Center for Diseases Control and Prevention. Guideline for Evaluating Insecticide Resistance in Vectors using the CDC Bottle Bioassay. Atlanta: Center for Diseases Control and Prevention; 2010.

15. Cui F, Raymond M, Qiao CL. Insecticide resistance in vector mosquitoes in China. Pest Manag Sci. 2006; 62: 1013-22

16. Hemingway J, Hawkes NJ, McCarroll L, Ranson L. The molecular basis of insecticide resistance in mosquitoes. Insect Biochemistry and Molecular Biology. 2004; 34: 653-65

17. Srisawat R, Komalamisra N, Eshita Y, Zheng M, Ono K, et al. Point mutations in domain II of the voltage-gated sodium channel gene in deltamethrin-resistant Aedes aegypti (Diptera: Culicidae). Appl Entomol Zool. 2010; 45: 275-82.

18. Aung TT, Win S, Aung S. Status report on epidemiology of dengue/ dengue haemorrhagic fever in Myanmar. Dengue Bull. 1995; 20 : 41-5

19. Nauen R. Insecticide resistance in disease vectors of public health importance. Pest Manag Sci. 2007; 63: 628-33.

20. Kawada H. New mosquito control techniques as countermeasures against insecticide resistance. In: Perveen F, editor. Insecticides Advances in Integrated Pest Management. London: InTech; 2012. p.657-82. 